\title{
3D NUMERICAL MODEL IN NONLINEAR ANALYSIS OF THE INTERACTION BETWEEN SUBSOIL AND SFCR SLAB
}

\author{
* Jana LABUDKOVA ${ }^{1}$, Radim CAJKA ${ }^{2}$ \\ ${ }^{1,2}$ Faculty of Civil Engineering, VSB - Technical University Ostrava, Department of Structures, Ludvika \\ Podeste 1875/17, 70833 Ostrava - Poruba, Czech Republic
}

*Corresponding Author, Received: 16 May 2016, Revised: 12 July 2016, Accepted: 22 Nov. 2016

\begin{abstract}
For decades attention has been paid to interaction of foundation structures and subsoil and, in turn, to development of interaction models. Complexity of a static solution is given mainly by selection of a computational model, effects of physical-nonlinear behaviour of such structure and co-effects of the upper structure and the foundation structure. ). Input data for numerical analysis were observed experimental loading test of steel-fibre reinforced concrete slab. The loading was performed using unique experimental equipment which was constructed in the area Faculty of Civil Engineering, VŠB-TU Ostrava. Homogeneous half-space this takes no account and calculated settlement is strongly dependent on the size of the subsoil model, as parametric study demonstrated. The modulus of deformability changes continuously, depending on the depth, in the inhomogeneous half-space. Values calculated by 3D numerical model were compared with values measured during the loading test of steel-fibre concrete slab.
\end{abstract}

Keywords: Foundation structure, Soil - structure interaction, Contact stress, 3D FEM element.

\section{INTRODUCTION}

Input characteristics of applied material models in subsoil-structure interaction often have lower levels of reliability (especially in the case of the subsoil). This can lead to a lower level of reliability of results of modeling. For this purpose, research and experimental measurements focused on the settlement of loaded foundation soil, deformations of the slabs in interaction with subsoil and dependence of stress in the slabs on the characteristics of the subsoil are still performed. Because calculated subsidence and real subsidence of foundations do not correlate well $[9,10,17,18]$, a site survey is needed and experimental measurements are carried out in order to determine subsidence of foundation soil under structures, deformation of foundation slabs and characteristics of stress in foundation slabs which depend on parameters of subsoil. Using results of such experiments, the methods used for calculation of subsidence are modified and become stricter. In 2010, testing equipment - a stand, was erected in the Faculty of Civil Engineering, VŠB TU Ostrava [15]. The stand measures deformation and monitors interaction between stress and deformation. In 2014 an experiment was carried out using the stand. Values measured during the loading tests were compared with values calculated by interaction 3D FEM models. The calculations were carried out for several sizes of the subsoil and for different boundary conditions. The values were compared and impacts of 3D numerical model parameters on final deformation and internal forces in the steel-fibre reinforced foundation slab were evaluated. Another experimental loading tests and their results are also described in $[2,3,6,7,8,11$, $19,20,21]$.

\section{EXPERIMENTAL LOADING TEST OF STEEL-FIBRE REINFORCED CONCRETE SLAB}

A sample used for the experiment and for monitoring of foundation - subsoil interaction was a steel-fibre reinforced concrete slab. The size of the fibre concrete slab was 2000 × 2000 x $170 \mathrm{~mm}$. The $\mathrm{C} 25 / 30$ concrete was cast there - it was reinforced with scattered reinforcement. The reinforcement consisted of steel fibres, 3D DRAMIX 65/60B6-25 $\mathrm{kg} \cdot \mathrm{m}^{-3}$. The slab casting process is shown in Fig. 1.

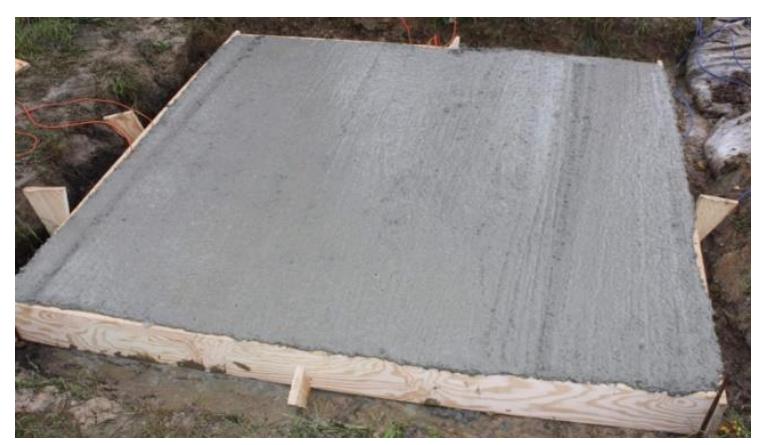

Fig. 1 Casting of the steel-fibre reinforced concrete slab 
The upper layer of subsoil consists of loess loam with F4 consistency. Thickness of that layer is about 5 meters. Poisson coefficient of the subsoil is $\mu=0.35$, and modulus of deformability is $\mathrm{E}_{\mathrm{DEF}}=$ 23.7 MPa. From the geologic point of view, foundation soil is not complex.

During the test, the fibre concrete slab was loaded in the middle by the pressure applied by the hydraulic press. Dimensions of the area under load were $200 \times 200 \mathrm{~mm}$. The loading was carried out in steps: $50 \mathrm{kN} / 30$ minutes. The slab failed during the $6^{\text {th }}$ cycle when the loading force was $250 \mathrm{kN}$. The model of steel-fibre reinforced concrete foundation slab was violated by punching shear. Punching shear of slabs is discussed in detail [1].

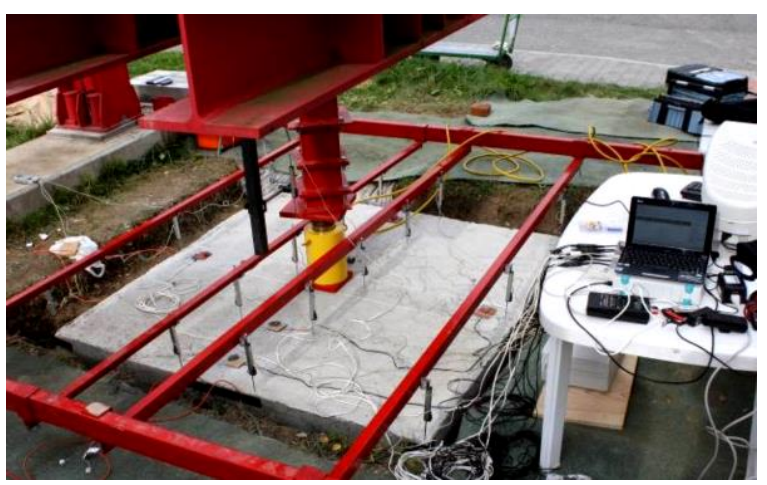

Fig. 2 Load test of the steel-fibre concrete slab

\section{3D COMPUTATIONAL MODEL IN ANSYS SYSTEM}

A 2D element, SHELL 181, was chosen for the foundation slab which was modelled as a surface with the specified slab thickness. The subsoil was modelled using a 3D element, SOLID 45. The material properties were modelled using the modulus of elasticity $\mathrm{E}$ (or the modulus of deformability $\mathrm{E}_{\mathrm{DEF}}$ in case of soil) and Poisson coefficient $\mu$.

In connection with the creation of a spatial model using 3D elements is particularly problematic correctly to determine the size of the modeled area representing the subsoil, to choose boundary conditions and finite size mesh.

Soil is inhomogeneous and its properties are different from idealised properties of an elastic isotropic and homogeneous substance. In the homogeneous half-space, the modulus of deformability is constant and does not depend on depth (Fig. 3). In the inhomogeneous half-space, the concentration of vertical stress in the foundation axis is different from that in the homogeneous half-space. The modulus of deformability changes continuously, depending on the depth. This means that it is the model of the inhomogeneous half-space which describes the deformation behaviour of the soil better that the homogeneous model. Using of inhomogeneous half-space is also described in papers [12, 13, 14]. Homogeneous half-space and also inhomogeneous half-space were used in numerical analyses.
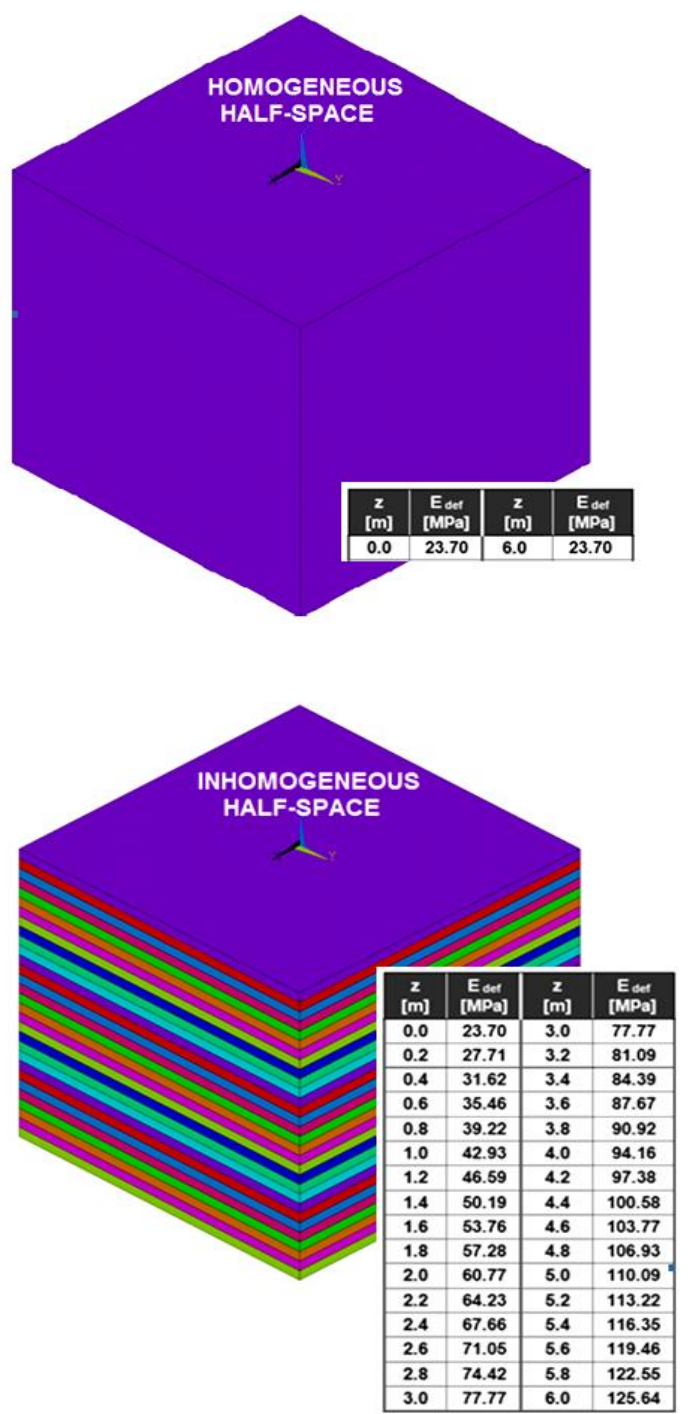

Fig. 3 3D numerical model in ANSYS

Shell 181 is a four-node element with six degrees of freedom in a node. The degrees of freedom represent three dislocations in $\mathrm{x}, \mathrm{y}$ and $\mathrm{z}$ axes and three torsional displacements around $\mathrm{x}, \mathrm{y}$ and $\mathrm{z}$ axes. SOLID 45 is defined by eight nodes where each node is characterised by three degrees of freedom (dislocations of the node in $\mathrm{x}, \mathrm{y}$ and $\mathrm{z}$ axes). Dead 
weight of soil and dead weight of concrete slab were not considered for the calculation. The slab and subsoil were modelled using the regular finiteelement mesh. The sizes of mesh elements were different for the subsoil and for the slab surface where the mesh was denser. The force was specified for each node in the finite-element mesh of the slab. The location and value corresponded to the load applied onto the slab during the experiment. In order to transfer effects of the load, which was applied on the foundation slab, into the subsoil it was essential to create a mutual contact and define a contact surface. The FEM model was solved using the contact elements.

Contact elements mediate the kinematic process of deformation. The contact was created using the contact pair: TARGE170 - CONTA173. Friction between the slab and subsoil was neglected there.

\section{PARAMETRIC STUDY}

In connection with the creation of a spatial model using 3D elements is particularly problematic correctly to determine the size of the modeled area representing the subsoil, to choose boundary conditions and finite size mesh. A dependence deformation on these parameters was proved by parametric study. Two aspects were considered when comparing different models. One aspect is dependence of deformation on variable depth of the subsoil, while keeping the same ground plan of the subsoil. The second aspect is dependence of

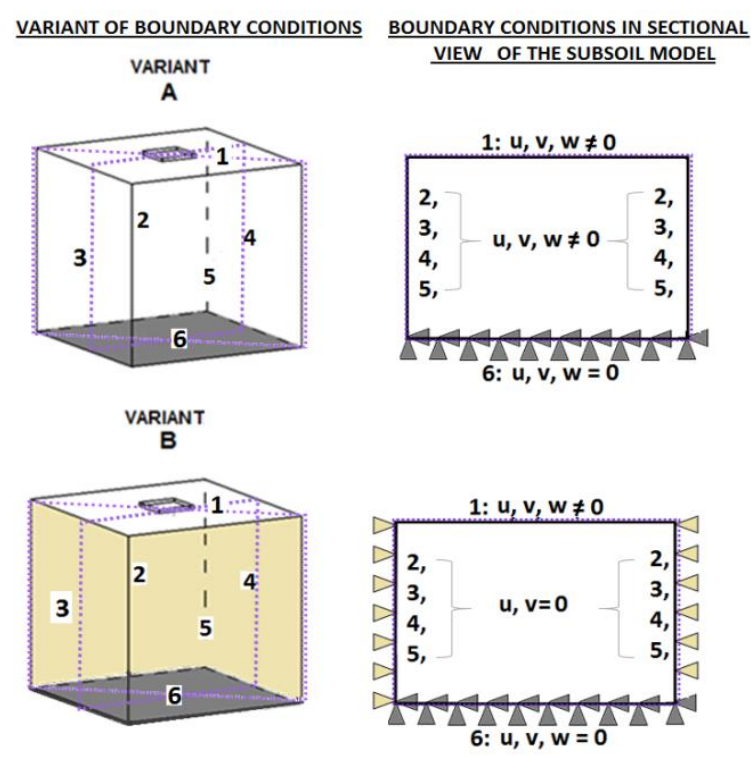

deformation on variable size of ground plan of the subsoil, while keeping the same depth. The comparison was made for three different boundary
C
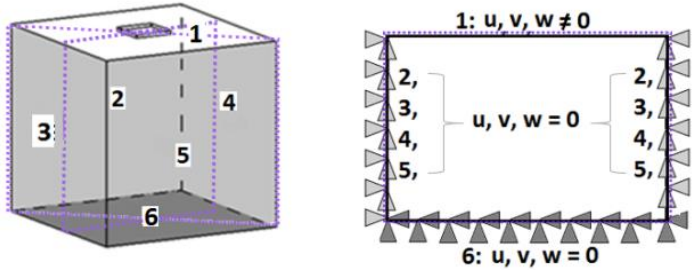

conditions - see Fig. 4, Fig. 5.

Fig. 4 Variant of boundary condition A, B

Fig. 5 Variant of boundary condition C

\subsection{Deformation versus variable depth of the subsoil model}

Fig. 6 - Fig. 8 compares the deformations of the slab for the variable depth of the homogeneous halfspace (light curve) and inhomogeneous half-space (dark curve) for all variants of the boundary conditions.

The ground plan is $6.0 \times 6.0 \mathrm{~m}$ and boundary

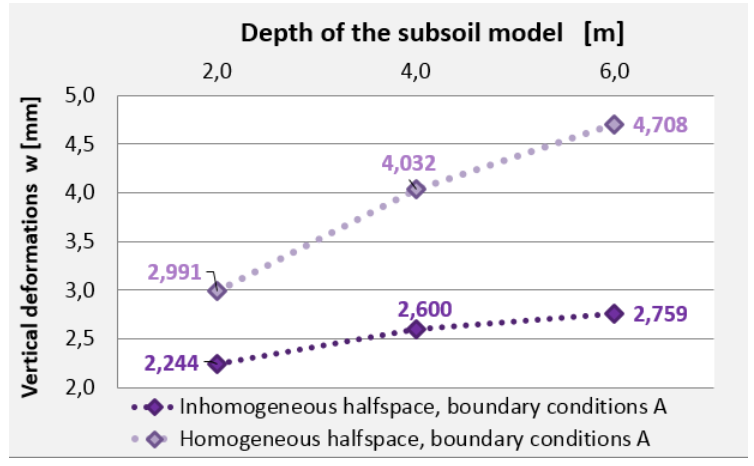

conditions are $\mathrm{A}$ :

Fig. 6 Deformation versus variable depth of the subsoil model, boundary conditions A

The ground plan is $6.0 \times 6.0 \mathrm{~m}$ and boundary

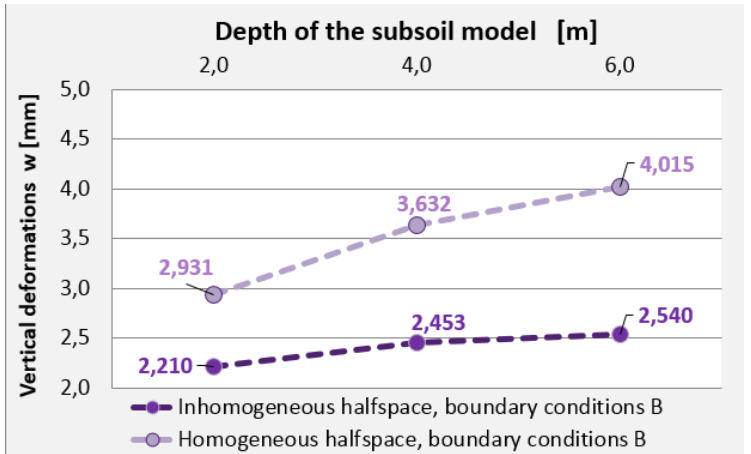

conditions are B:

Fig. 7 Deformation versus variable depth of the subsoil model, boundary conditions B 
The ground plan is $6.0 \times 6.0 \mathrm{~m}$ and boundary conditions are $\mathrm{C}$ :

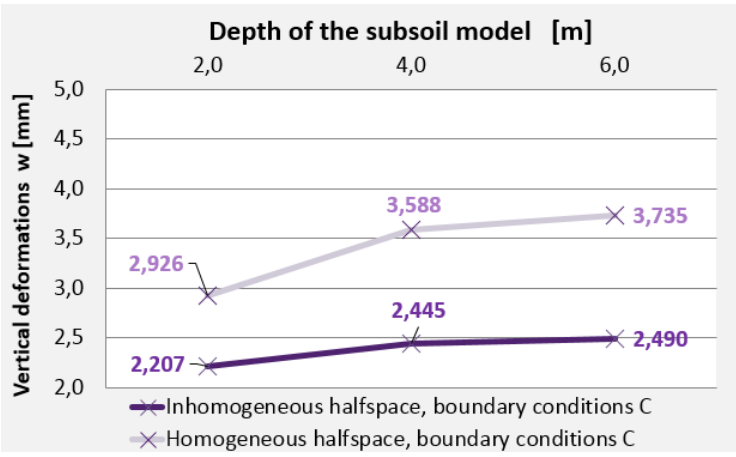

Fig. 8 Deformation versus variable depth of the subsoil model, boundary conditions $\mathrm{C}$

\subsection{Deformation versus variable ground plan of the subsoil}

Fig. 9 - Fig. 11 compares the deformations of the slab for the variable ground plan of the homogeneous half-space (light curve) and inhomogeneous half-space (dark curve) for all variants of the boundary conditions.

The depth is $6.0 \mathrm{~m}$ and boundary conditions A:

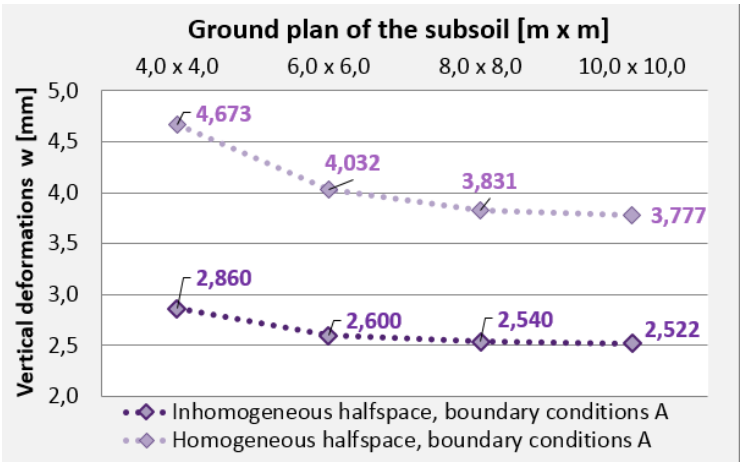

Fig. 9 Deformation versus variable ground plan of the subsoil, boundary conditions A

The depth is $6.0 \mathrm{~m}$ and boundary conditions $\mathrm{B}$ :

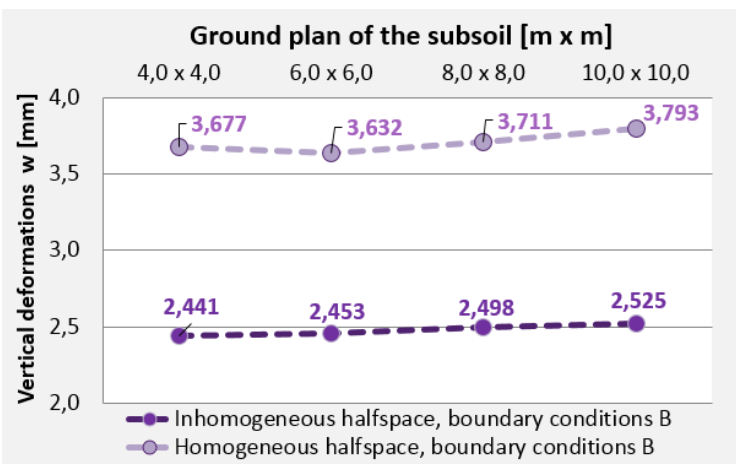

Fig. 10 Deformation versus variable ground plan of the subsoil, boundary conditions B
The depth is $6.0 \mathrm{~m}$ and boundary conditions $\mathrm{C}$ :

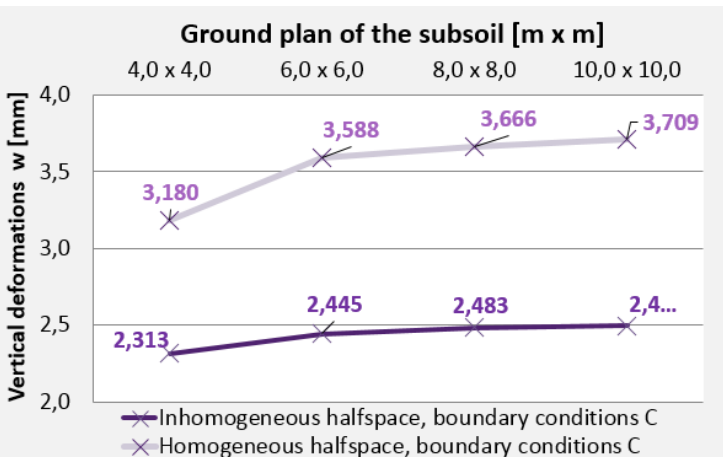

Fig. 11 Deformation versus variable ground plan of the subsoil, boundary conditions $\mathrm{C}$

The deformation in the middle of the steel-fibre reinforced concrete slab measured during the experiment was ca. $2.83 \mathrm{~mm}$.

It follows from the characteristics deformation vs. variable depth of the subsoil model that the increasing depth results in increases in the vertical deformation. Considering different variants of the boundary conditions, one can compare the growth of vertical deformation once the depth becomes higher (Fig. 12).

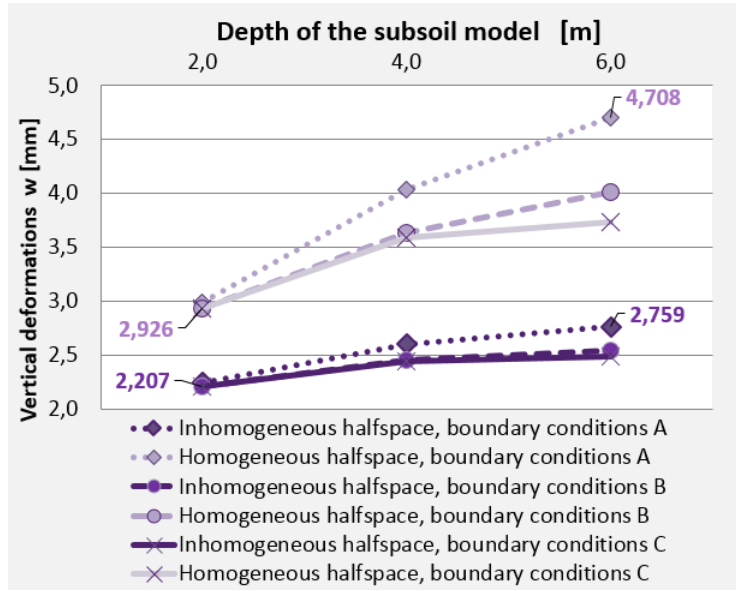

Fig. 12 Deformation versus variable depth of the subsoil model, all boundary conditions

In case of the variant $\mathrm{C}$ when all walls except for the upper surface are fixed, the boundary conditions play such an important role that even the increasing depth does not increase the vertical deformation so much as for other variants of boundary conditions. On the other hand, the least influence of boundary condition was for the variant $\mathrm{A}$, when deformation is possible for each wall of the subsoil model in each direction except for the lower base which is fixed. Fig. 12 shows that the higher the depth of the subsoil 
model is, the bigger the difference is between deformations calculated for the variants of boundary conditions. With the increasing depth of the subsoil model, the selection of boundary conditions is becoming a more important criterion which influences the final vertical deformation.

An important lesson learnt from characteristics describing the deformation versus variable size of subsoil ground plan is that the influence of any boundary condition is becoming weaker with the increasing ground plan of the subsoil. Using the chart in Fig. 13 it can be concluded that the boundary conditions play no role at all, if the ground plan of the subsoil model is big enough.

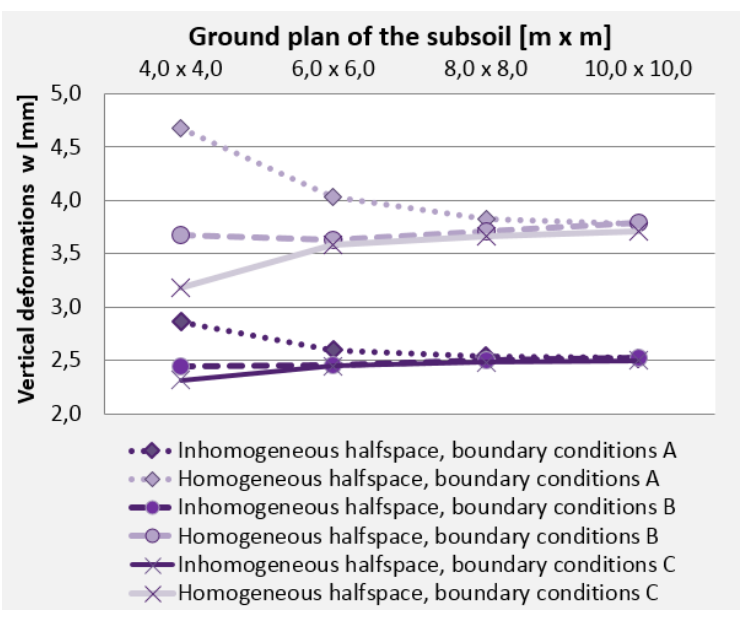

Fig. 13 Deformation versus variable ground plan of the subsoil model, all boundary conditions

Even in that case the boundary conditions influence the characteristics the deformation versus the increasing ground plan of the subsoil model which has been proved by the chart in Fig. 13.

The charts prove the major role played by the size of the model area and by the boundary condition itself. Results were quite scattered for the variants. Charts in Fig. 12 and 13 indicate how the parameters of the area influence considerably the resulting vertical deformation.

From deformations obtained by numerical subsoil model of homogeneous half-space, the conclusion can be drawn that the values of deformation resulting from the 3D model are too scattered. Final deformation measured during the experiment was ca. $2.83 \mathrm{~mm}$. In this set of results in Fig. 12 and Fig 13 the vertical deformation is ranges from 2.926 to $4.708 \mathrm{~mm}$ in analyses of homogeneous half-space. This is really great variance in the resulting deformation depending on the size of the subsoil model and its boundary conditions. Fig. 12 and Fig 13 the vertical deformation is ranges from 2.207 to $2.759 \mathrm{~mm}$ in analyses of inhomogeneous half-space. This is not so really great variance in the resulting deformation depending on the size of the subsoil model and its boundary conditions as in analyses of homogeneous half-space. This means that the inhomogeneous continuum provides more stable results which are less affected by the choice of the geometry and dimensions of the area representing the subsoil.

\section{CRACKED CONCRETE MATERIAL MODEL IN NONLINEAR ANALYSES}

For the foundation slab, which is also modelled using the 3D element SOLID 65. The SOLID 65 element has eight nodes. SOLID 65 allows spatial modelling of solids with reinforcement elements. That was the reason why SOLID 65 was used for modelling a slab made of steel fibre reinforced concrete. SOLID65 allows non-linear calculation of concrete structures by Willam and Warnke. This model of behaviour of quasi-brittle material captures both thrust damage (forming cracks) and pressure damage (crushing the material). SOLID 65 is appropriate to demonstrate the actual behaviour of steel-fibre reinforced concrete. Solid 65 allows solutions with nonlinear material properties. The element can be used to take into account a plastic deformation, tearing in three orthogonal directions or shredding the material. At the beginning of the calculation, the material element (concrete) is considered homogeneous and isotropic. If the condition for thrust damage is fulfilled at any integration point of the finite element, the rigidity is gradually reduced. The condition of pressure damage is applied similarly. The parameters entered in the calculation are shown in Fig. 14 and Fig. 15. The parameters for the concrete are in Fig. 14.

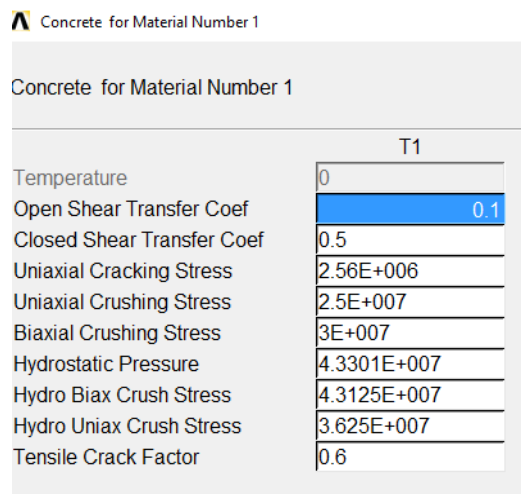

Parameters for the concrete model
Fig. 14 
The parameters of the scattered reinforcement are in Fig. 15, and at bottom, there is a diagram of the geometry of the finite element SOLID 65.

\begin{tabular}{|c|c|c|}
\hline \multicolumn{3}{|c|}{ Element Type Reference No. 1} \\
\hline \multicolumn{2}{|c|}{ Real Constant Set No. } & \begin{tabular}{|l}
1 \\
\end{tabular} \\
\hline \multicolumn{3}{|c|}{ Real constants for rebar 1} \\
\hline Material number & MAT1 & 3 \\
\hline Volume ratio & VR1 & 0.008 \\
\hline Orientation angle & THETA1 & 90 \\
\hline Orientation angle & PHI1 & 0 \\
\hline
\end{tabular}

Real constants for rebar 2

Material number MAT2

Volume ratio VR2

Orientation angle THETA2

Orientation angle $\quad \mathrm{PHI}$

Real constants for rebar 3

Material number MAT3

Volume ratio VR3

Orientation angle THETA3

Orientation angle $\mathrm{PHI}$

Crushed stiffness factor CSTIF

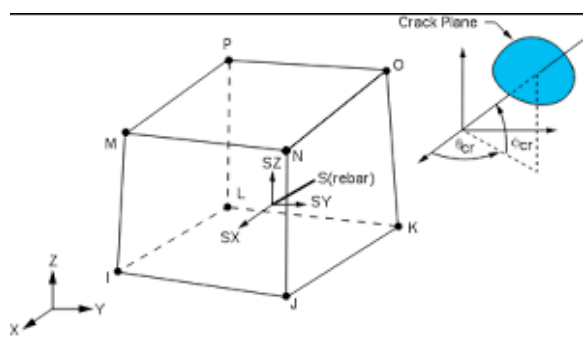

Fig. 15 Parameters for the SOLID 65

Fig. 16 shows a schematic layout of fibres in the model of the concrete slab using the 3D finite element SOLID 65, where the distribution of fibres is modelled evenly and in all three directions.

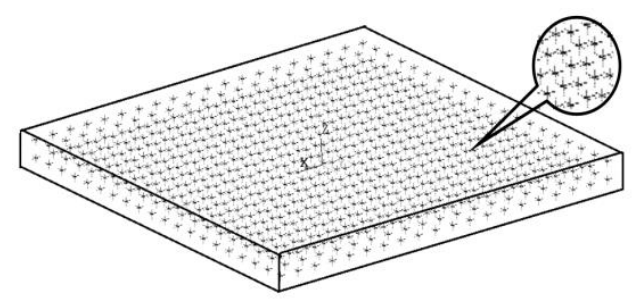

Fig. 16 Fibres in the model of the slab using the 3D element SOLID 65

The comparison of slab model without influence of reinforcement and cracks with slab model with influence of reinforcement and cracks is shown in following figures. The comparison is made for inhomogeneous subsoil model $6.0 \times 6.0 \times 6.0 \mathrm{~m}$ and variant of boundary conditions $B$. The following figure (Fig. 17) shows the deformation of the model slab with the application of the 3D finite element SOLID 45 without consideration of the impact of fibres and cracks. Because of the way of loading the central part of the slab, there are also maximum vertical deformations in the central part of the slab (marked with the red area). The maximum deformation in the middle of the slab has a value of $2.97 \mathrm{~mm}$.

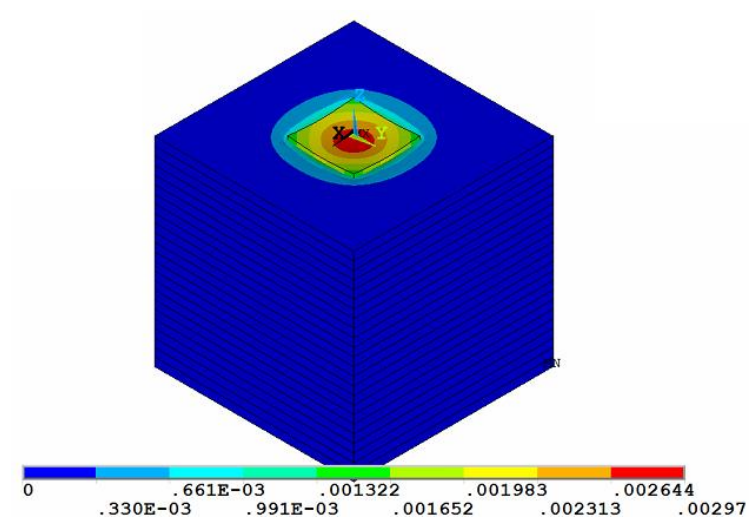

Fig. 17 Deformation of the slab model (modelled by SOLID 45) placed on the subsoil model

The following figure (Fig. 18) represents a magnified view of the deformation of the model slab. As a result of the use of the SOLID45 element, which does not take into account the influence of cracks, the model slab is not damaged by cracks (Fig. 18 , below).
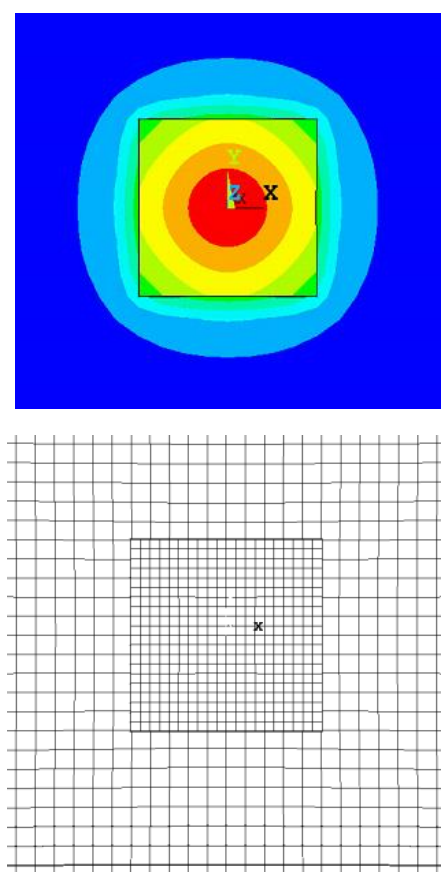

Fig. 18 Magnified view of the deformation of the model slab with no cracks 
Fig. 19 shows the deformation of the model slab with the application of the 3D finite element SOLID 65 with consideration of the impact of fibres and cracks (placed the model subsoil for the above mentioned boundary conditions). Because of the way of loading the central part of the slab, there are also maximum vertical deformations in the central part of the slab (marked with the red area). The maximum deformation in the middle of the slab has a value of $5.795 \mathrm{~mm}$.

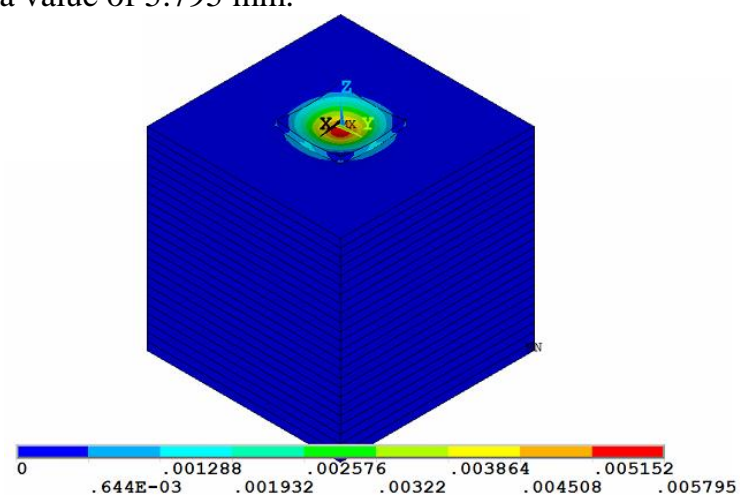

Fig. 19 Deformation of the slab model (modelled by SOLID 65) placed on the subsoil model

Fig. 20 represents a magnified view of the deformation of the model slab placed on the model subsoil. As a result of the use of the SOLID65 element that allows thrust damage (crack formation) and pressure damage (crushing the material), it is also possible to draw the model of the slab damaged by cracks. In the figure (Fig. 20, below), the area damaged by indented cracks is also marked.
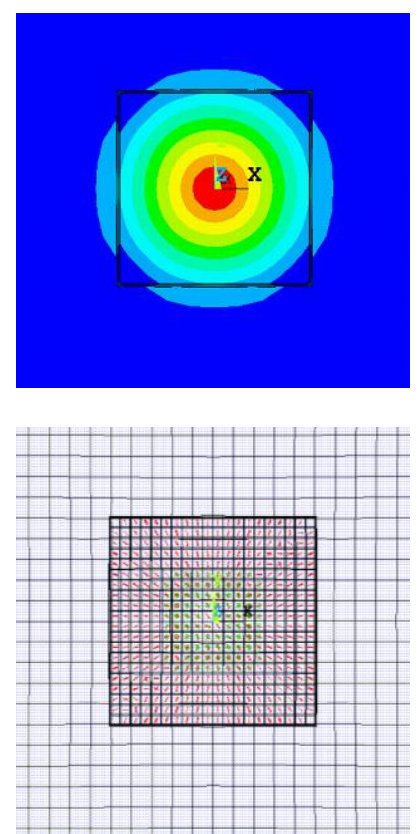

Fig. 20 Magnified view of the deformation of the model slab with cracks

\section{CONCLUSIONS}

The model of the inhomogeneous continuum provides smaller vertical deformations than the model of the homogeneous continuum. This is evident from the graph in Figure 12 and Figure 13. This is a consequence of the modulus of deformability which increases with the depth. A parametric study was conducted in which was monitoring the impact of the geometrical dimensions of the subsoil model (depth of the subsoil model an also ground plan dimensions of the subsoil model) and variants of boundary conditions. It was demonstrated, that the inhomogeneous continuum provides more stable results which are lot less affected by the choice of the geometry and dimensions of the area representing the subsoil.

Numerical analysis of subsoil-structure interaction based on the finite element method (FEM) was performed in the program ANSYS. In the numerical analysis, the effect of fibre reinforced concrete using the element SOLID 65 was monitored. SOLID65 element allows tensile damage (crack formation) and pressure damage (crushing the material) in the numerical slab model. It was also compared with the numerical analysis, in which the slab made of steel fibre reinforced concrete was modelled using the 3D finite element SOLID45, which did not reflect the impact of fibres or crack formation. Numerical model slab with the application of the 3D finite element SOLID 45 without consideration of the impact of fibres and cracks provides the resulting deformation of the slab model smaller than SOLID 65 with influence of cracks. The reason is the consideration of the fibres in concrete, nonlinear behaviour of fibres concrete and influence of cracks.

\section{ACKNOWLEDGEMENTS}

This outcome has been achieved with the financial support of the project GACR No. 1608937S ,State of stress and strain of fiber reinforced composites in interaction with the soil environment". In this undertaking, theoretical results gained by conceptual development of research, development and innovations for 2016 at the VŠB-Technical University of Ostrava (granted by the Ministry of Education, Youths and Sports of the Czech Republic) were partially exploited. 


\section{REFERENCES}

[1] R. Halvonik, J., Fillo, "The Maximum Punching Shear Resistance of Flat Slabs, Procedia Engineering”, vol.: $\quad 65, \quad 2013$, pp 376-381, ISSN 1877 - 7058,

[2] M. Aboutalebi, A. Alani, J. Rizzuto, D. Beckett, "Structural behaviour and deformation patterns in loaded plain concrete ground-supported slabs". Structural Concrete. 2014, vol. 15, issue. 1, pp. 81-93. ISSN 1464-4177.

[3] T. Clément, A.P. Ramos, M.F. Ruiz, A. Muttoni, "Influence of prestressing on the punching strength of post-tensioned slabs", Engineering Structure, vol. 72, pp. 56-69 (14 p), ISSN: 0141-0296, 2014

[4] K. Frydrysek, R. Janco, H. Gondek, "Solutions of Beams, Frames and 3D Structures on Elastic Foundation Using FEM", International Journal of Mechanics, Issue 4, Vol. 7, p. 362-369, 2013.

[5] P. Mynarcik, "The Subsidence Analysis of Experimental Post-tensioned Concrete Slab Model in the Course of the Static Load Test", Applied Mechanics and Materials, vol. 744 - 746, pp. 15561559 (4 p), Trans Tech Publications, Switzerland, 2015.

[6] A. Alani, M. Aboutalebi, "Analysis of the subgrade stiffness effect on the behaviour of ground-supported concrete slabs" Structural Concrete, Issue 13, Volume 2, pages 102-108, DOI: 10.1002/suco.201100043, 2012.

[7] R. Cajka, R. Fojtik, "Development of Temperature and Stress during Foundation Slab Concreting of National Supercomputer Centre IT4", Procedia Engineering, vol. 65, 2013, pp. 230-235 (6 p), ISSN 1877-7058,

[8] R. Cajka, K. Burkovic, V. Buchta, "Foundation Slab in Interaction with Subsoil", Advanced Materials Research, Vols. 838-841, pp. 375-380, Trans Tech Publications, Switzerland, 2014.

[9] R. Cajka, J. Labudkova, „Influence of parameters of a 3D numerical model on deformation arising in interaction of a foundation structure and subsoil", (COSTMA '13), Budapest, Hungary, 2013.

[10] R. Cajka, P. Mateckova, "Comparison of calculating methods and consequent carrying capacities of prestressed precast concrete roof purlin", in proceedings of First International Workshop "Design of Concrete Structures using EN 1992-1-1, Prague, 15 March 2010, ISBN 978-80-01-04581-7, WOS: 000324078100017.

[11] M. Janulikova, R. Cajka, P. Mateckova, V. Buchta, "Laboratory Testing of Asphalt Belts Rheological Properties Exposed to Shear Loads", Transactions of the VŠB - Technical University of Ostrava, Civil
Engineering Series, vol. XII, iss. 2, pp. 59-66 (8 p), ISSN (Online) 1804-4824, ISSN (Print) 1213-1962.

[12] K. Zhou , W. W. Chen, L. M. Keer, X. Ai, K. Sawamiphakdi, P. Glaws, Q. J. Wang, "Multiple 3D inhomogeneous inclusions in a half space under contact loading", Mechanics of Materials, Vol. 43, Issue 8, Pages 444-457, 2011.

[13] V. I. Fabrikant, T. S. Sankar, „On contact problems in an inhomogeneous half-space", International Journal of Solids and Structures, Volume 20, Issue 2, Pages 159-166, 1984.

[14] K. Zhou, W. W. Chen, L. M. Keer, X. Ai, K. Sawamiphakdi, P. Glaws, Q. J. Wang, ,Multiple 3D inhomogeneous inclusions in a half space under contact loading“, Mechanics of Materials, Vol- 43, Issue 8, pp.444-457, 2011.

[15] R. Cajka, V. Krivy, D. Sekanina, "Design and Development of a Testing Device for Experimental Measurements of Foundation Slabs on the Subsoil", Transactions of the VŠB - Technical University of Ostrava, Civil Engineering Series, vol. XI, iss. 1, pp. 1-6, ISSN 1804-4824, ISBN 978-80-248-2332-4.

[16] R. Cajka, "Analytical derivation of friction parameters for FEM calculation of the state of stress in foundation structures on undermined territories", Acta Montanistica Slovaca, vol. 18, iss. 4, pp. 254261 (8 p), ISSN: 13351788, 2013.

[17] R. Cajka, J. Labudkova, „Dependence of deformation of a plate on the subsoil in relation to the parameters of the 3D model", International Journal of Mechanics, Volume 8, Pages 208-215, 2014, ISSN: 1998-4448.

[18] J. Labudkova, R. Cajka, "Comparsion of Measured Displacement of the Plate in Interaction with the Subsoil and the Results of 3D Numerical Model", Advanced Material Research, vol. 1020, pp. 204-209 (6 p), Trans Tech Publications, Switzerland, ISSN (Online) 1662-8985, ISSN (Print) 1022-6680, 2014.

[19] Cajka, K. Burkovic, V. Buchta, R. Fojtik, "Experimental soil - Concrete plate interaction test and numerical models", Key Engineering Materials, vol. 577-578, pp. 33-36 (4 p), Trans Tech Publications, Switzerland, 2014.

[20] Cajka, R. - Labudkova, J. - Mynarcik, P.: Numerical solution of soil - foundation interaction and comparison of results with experimental measurements, International Journal of GEOMATE, July, 2016, Vol. 11, Issue 23, pp. 2116-2122, Geotec., Const. Mat. \& Env., ISSN: 2186-2982(Print), 21862990(Online), Japan.

[21] Cajka, R. - Mynarcik, P. - Labudkova, J.: Experimental measurement of soil-foundation interaction, International Journal of GEOMATE, June, 2016, Vol. 10, Issue 22, pp. 2101-2108, Geotec., Const. Mat. \& Env., ISSN: 2186-2982(Print), 21862990(Online),

Japan.

Copyright (C) Int. J. of GEOMATE. All rights reserved, including the making of copies unless permission is obtained from the copyright proprietors. 